\title{
Ongoing Health Inequality in Aboriginal and Torres Strait Islander Population in Australia:Stressful Event, Resilience, and Mental Health and Emotional Well-Being Difficulties
}

\author{
Jing Sun ${ }^{1, *}$, Nicholas Buys ${ }^{2}$, Dion Tatow ${ }^{3}$, Lindsay Johnson ${ }^{4}$ \\ ${ }^{1}$ School of Public Health and Griffith Health Institute. Griffith University, Logan campus, Meadowbrook, Brisbane, O4131, Australia \\ ${ }^{2}$ School of Human Services and Social Work and Griffith Health Institute, Griffith University, Gold Coast campus, Parkland, Gold Coast, \\ Q4222, Australia \\ ${ }^{3}$ Queensland Aboriginal and Islander Health Council, Brisbane, Australia \\ ${ }^{4}$ Kambu Medical Services Inc, Ipswich , Australia
}

\begin{abstract}
This study aims to examine psychosocial factors associated with mental health and emotional well-being difficulties in a group of Aboriginal and Torres Strait Islander adults. A self-reported survey was administered to 155 participants aged 18-80 from five Indigenous communities, who were recruited through local Aboriginal Community Controlled Health Services. Stress, resilience, mental health and emotional well-being were measured. Structural Equation Modelling was used to analyse the association of stress and resilience with mental health and emotional well-being difficulties. Seventy-eight participants had no mental health or emotional well-being difficulties but 77 participants were at risk. Low levels of resilience emerged as a key psychosocial factor associated with mental health and emotional well-being difficulties while high levels of resilience were associated with a reduced risk. High levels of stress was related to an increased risk of experiencing mental health and emotional well-being difficulties. Improving our understanding of psychological characteristics associated with resilience in the face of stress can inform prevention and treatment interventions for stress-exposed individuals.
\end{abstract}

Keywords Depression, Social And Emotional Wellbeing Difficulties, Resilience, Mental Health

\section{Introduction}

The poor health of Australia's Aboriginal and Torres Strait Islander people relative to the nation's population is well documented. On average, they live 17 years less than other Australians and suffer higher rates of nearly every type of illness and injury ${ }^{(1)}$. Australia has approximately 450,000 Indigenous people, which make up $2.4 \%$ of the population. Urban, rural and remote Indigenous communities around Australia continue to experience what are at times overwhelming levels of grief, loss and trauma, which strongly affect their social and emotional well-being, and their mental health ${ }^{(2)}$. In studies in other populations, stressful events have been found to increase the risk for a range of psychiatric disorders ${ }^{(3)}$. Studies have shown that Aboriginal and Torres Strait Islander individuals have high rates of exposure to

* Corresponding author: j.sun@griffith.edu.au (Jing Sun)

Published online at http://journal.sapub.org/ijpbs

Copyright (C) 2012 Scientific \& Academic Publishing. All Rights Reserved negative stressful events and in particular to collective trauma due to colonisation and disadvantage(4). However, there are no published studies that examine mental health and emotional well-being associated with specific types of stress in Aboriginal and Torres Strait Islander adults.

Resilience factors have been associated with reduced risk of mental health problems and coping with adversity ${ }^{(5)}$. Studies have also shown that many people are able to adapt with minimal disruption to their lives and others are eventually able to recover their baseline level of functioning after a symptomatic period ${ }^{(6)}$. Resilience is defined as 'a pattern over time, characterized by good eventual adaptation despite developmental risk, acute stress, or chronic adversities ${ }^{(7)}$. The resilient person is characterised as one with various internal strengths or assets coupled with access to environmental resources such as supportive adults. The potential for positive change following trauma and adversity appears to be determined by subjective interpretations of the event (for example, helplessness, controllability and life threat) and external factors (for example, social support). In this study, resilience is considered in a broad cultural context com- 
prising individual, family and community characteristics. It maintains that resilience is affected substantially by social relationships and is a function of the quality of those relationships. Individuals are interconnected within and across multiple contextual systems that engage in ongoing transactions, thereby mutually influencing each other ${ }^{(8)}$. The study of stress in populations at high risk, such as Aboriginal and Torres Strait Islander populations provides a unique opportunity to examine psychosocial characteristics associated with resilience. The present study was conducted in a sample of Aboriginal and Torres Strait Islander adults exposed to a range of stresses. This study was based on baseline data collected as part of a prospective intervention study in promoting social and emotional well-being in Aboriginal and Torres Strait Islander people. Based on previous research, we expected that those with high levels of resilience and high levels of ability to cope with stress and to elicit social support from friends and community would be at lower risk of experiencing mental health and emotional well-being difficulties. Based on epidemiological research findings, we expected that multiple stresses would be related to such risk. Therefore, the study aimed to examine the relationship of stress and resilience with mental health and emotional well-being difficulties.

\section{Method}

\subsection{Participants}

Participants were recruited from five Aboriginal Community Controlled Health Services (CCHSs) in South East Queensland, comprising one rural, two urban and two regional services. Staff members approached the participants by mailing flyers and during the delivery of health services. Participants were then invited to provide consent for the study and join a project launch session to fill in the surveys. Participants were excluded from the study if they were unable to speak English, had an acute medical illness, pain or discomfort, or if they were less than 18 years old. The study was approved by the Griffith University Human Research Ethics Committee (GU Ref No: PBH/13/10/HREC).

\subsection{Measures}

All participants completed the following self-reported questionnaire. Items in the questionnaire were piloted to ensure participants understood the questions.

Stressful events (hereafter stress): The Negative Life Events Scale developed by the Australian Bureau of Statistics ${ }^{(9)}$ is a 15 -item scale used to measure the occurrence of stressful events in the past 12 months in Aboriginal and Torres Strait Islander populations and has high levels of reliability ${ }^{(10)}$. Scores range from 0 to 15 , with higher scores reflecting greater levels of reported stress.

Mental health and emotional well-being scale: The Indigenous Risk Impact Screen (IRIS) scale is a six-item scale used to assess mental health and emotional well-being and is designed for use with Aboriginal and Torres Strait Islander populations ${ }^{(11)}$. Scores range from 6 to 18 . Higher scores reflect greater levels of risk of experiencing mental health and emotional well-being difficulties, and a score of 11 is used as the cut-off point between low-and high-risk groups $^{(11)}$.

Resilience: Resilience was measured by two scales that were considered best for assessing the resilience concept in the present study. The Brief Resilience Scale is a five-item scale used to assess the individual's ability to bounce back and recover from stress ${ }^{(12)}$. The Social Support and Sense of Social Connectedness Scale consists of 10 items from the Social Support Index ${ }^{(13)}$. It was selected to assess the degrees to which Aboriginal and Torres Strait Islander people viewed the local community, family and friends as sources of support; believed that the community, family and friends could provide them with emotional, self-esteem and network support; felt valued by people in the community; and trusted people in the community.

Depression: Depression was measured by participants' self-reported depression status. To answer 'yes' for depression status, they needed to show evidence that they had been diagnosed by a psychiatrist on the Structured Clinical Interview for DSM-IV Axis I Disorders, Non-patient Edition $(\mathrm{SCID}-\mathrm{I} / \mathrm{NP})^{(14)}$.

Demographic factors: Factors including age, gender, income, education and marital status were measured as categorical variables and treated as potential confounding factors in the study.

\subsection{Data Analysis}

All analyses were performed using SPSS 19.0 and MPlus $2.0^{(15)}$. Lifetime stresses were estimated in the form of two variables: (a) the total number of stress categories endorsed (for example, serious accidents, death of family members, abuse, family member sent to jail, vandalism or malicious damage to property and discriminations/racism); and (b) the number of stresses on the following scale: no stress, one stress, two stresses and three or more stresses. Lifetime stress was compared across the two diagnostic groups (at risk of mental health and emotional well-being group versus normal group) with a Multivariate Analysis of Variances (MANOVA).

We delineated mental health and emotional well-being by defining two groups with scores in the following ranges on the IRIS scale ${ }^{(11)}$ : less than 11 as the normal group, 11 or more as the mental health and emotional well-being difficulty group. To examine which stress events were associated with mental health and emotional well-being, and whether this association is mediated by resilience, Structural Equation Modelling was used. The direct effect of stress on mental health and emotional well-being was analysed in the first model. In the second model, the indirect effect of stress on mental health and emotional well-being was analysed by adding resilience to the model to examine its mediating effect on the relationship between stress and mental health 
and emotional well-being. The significance of estimate is determined by a t-ratio of more than 1.96 and with a p-value of less than 0.05. Fit indices, such as small chi-square level, Comparative Fit Index (CFI) and Tucker Lewis index (TLI) of more than 0.90 and Root Mean Square Residual (RMSR) of less than $0.08^{(16)}$, are considered reasonable fits of the model.

The multiple correlations among questions enabled the use of MANOVA to examine which resilience, social support and social capital items were associated with mental health outcomes. In a MANOVA model, if there is an overall significant result, as indicated in the F-ratio and a p-value, univariate analysis of variance is further used to identify which variables contribute to the significant effect. However, as there were no differences between the normal and difficulty groups on all demographic variables in the study, these variables were not entered in the MANOVA models. All statistical tests were two-tailed, with a p-value of less than 0.05 considered statistically significant.

\section{Results}

Demographic characteristics are summarised in Table 1.

Table 1. Demographic characteristics

\begin{tabular}{|c|c|c|c|}
\hline Demographic Variables & $\operatorname{Normal}(\mathrm{N}=78)$ & $\begin{array}{l}\text { MH and Emotional well- } \\
\text { being difficulties }(\mathrm{N}=77)\end{array}$ & $\mathrm{P}$ \\
\hline \multicolumn{4}{|l|}{ Age Groups } \\
\hline $18-24$ & $8(10.4 \%)$ & $9(11.8 \%)$ & 0.37 \\
\hline $25-34$ & $16(20.8 \%)$ & $8(10.5 \%)$ & \\
\hline $35-44$ & $16(20.8 \%)$ & $18(23.7 \%)$ & \\
\hline $45-54$ & $10(13.0 \%)$ & $16(21.1 \%)$ & \\
\hline \multicolumn{4}{|l|}{ Sex } \\
\hline Male & $24(31.2 \%)$ & $26(34.2 \%)$ & 0.69 \\
\hline Female & $53(68.8 \%)$ & $50(65.8 \%)$ & \\
\hline \multicolumn{4}{|l|}{ Marital Status } \\
\hline Never Married & $30(39.0 \%)$ & $23(30.7 \%)$ & 0.11 \\
\hline \multicolumn{4}{|l|}{ Highest year completed at school } \\
\hline Did not go to school & $2(2.7 \%)$ & $2(2.7 \%)$ & 0.83 \\
\hline Year 9 or below & $22(29.3 \%)$ & $26(34.7 \%)$ & \\
\hline Year 10 or equivalent & $22(29.3 \%)$ & $16(21.3 \%)$ & \\
\hline Year 11 or equivalent & $10(13.3 \%)$ & $12(16.0 \%)$ & \\
\hline Year 12 or equivalent & $19(25.4 \%)$ & $19(25.3 \%)$ & \\
\hline \multicolumn{4}{|l|}{ Personal annual income } \\
\hline $\begin{array}{c}\$ 60,000 \text { or more }(\$ 1,150 \text { or } \\
\text { more / week })\end{array}$ & $0(0.0 \%)$ & $3(4.0 \%)$ & 0.25 \\
\hline $\begin{array}{c}\$ 20,000 \text { - } \$ 59,999(\$ 384- \\
\$ 1,149 / \text { week }) \\
\end{array}$ & $9(11.8 \%)$ & $10(13.3 \%)$ & \\
\hline Nil Income & $6(7.9 \%)$ & $7(9.3 \%)$ & \\
\hline Don't know & $29(38.2 \%)$ & $19(25.4 \%)$ & \\
\hline \multicolumn{4}{|l|}{ Highest qualification obtained } \\
\hline Non-trade certificate & $29(50.9 \%)$ & $26(50.0 \%)$ & 0.59 \\
\hline Trade certificate & $13(22.8 \%)$ & $11(21.2 \%)$ & \\
\hline Associate Diploma & $10(17.5 \%)$ & $5(9.6 \%)$ & \\
\hline Bachelor Degree & $3(5.2 \%)$ & $7(13.5 \%)$ & \\
\hline Postgraduate Diploma & $1(1.8 \%)$ & $1(1.9 \%)$ & \\
\hline Master's Degree & $1(1.8 \%)$ & $2(3.8 \%)$ & \\
\hline \multicolumn{4}{|l|}{ Identity } \\
\hline Aboriginal & $66(89.2 \%)$ & $64(85.3 \%)$ & 0.50 \\
\hline Torres Strait Islander & $3(4.1 \%)$ & $2(2.7 \%)$ & \\
\hline Aboriginal and Torres strait & $5(6.8 \%)$ & $9(12.0)$ & \\
\hline \multicolumn{4}{|l|}{ Region } \\
\hline Urban & $24(32.4 \%)$ & $16(21.3 \%)$ & 0.29 \\
\hline Regional & $34(45.9 \%)$ & $38(50.7 \%)$ & \\
\hline Rural & $16(21.6 \%)$ & $21(28.0 \%)$ & \\
\hline
\end{tabular}

Note. Comparisons were made for categorical data using chi square analysis. \# Age is mean and SD, t test was used to compare the difference between normal and mental health and emotional wellbeing difficulties group 
All 155 participants identified themselves as Aboriginal and/or Torres Strait Islanders. There were 68\% $(\mathrm{n}=116)$ female participants. Nearly half $(\mathrm{n}=73,42.9 \%)$ of the participants were married, $74 \%(\mathrm{n}=125)$ had an education level of less than 12 years and $55.4 \%(\mathrm{n}=93)$ had an annual family income of less than $\$ 40,000$. The ages of participants ranged from 18 to 86 with an average age of 46 .

Of the 155 Aboriginal and Torres Strait Islanders surveyed, $77(49.7 \%)$ had a mental health and emotional well-being score of 11 and greater based on their results on the IRIS scale described above and were therefore classified in the mental health and emotional well-being difficulty group. The 78 participants $(50.3 \%)$ with an IRIS score of 10 or less were classified into the normal mental health group. We compared the two groups on demographics and stressful event exposure, using t-tests for continuous variables and chi-square tests for categorical variables.

The two groups did not differ significantly on any of the demographic characteristics of gender, age, marital status, education and income. The mental health and emotional well-being difficulty group consisted primarily of people with depressive, anxiety and substance use disorders. By definition, the normal mental health group had no lifetime history of psychiatric disorders. In the former group, 20
(50.1\%) had more than one clinically diagnosed comorbid current psychiatric disorder. Mean current and lifetime stress scores for each group are listed in Table 2, which also lists the stress categories. The exposure to stressful events in the past 12 months and the mean total number of stress categories were significantly different in the two groups (Table 2).

Table 2 also shows the results of logistic regression analyses examining stress in association with mental health and emotional well-being difficulties, with the normal mental health group as the reference group. There are 29.3\% of Aboriginal and Torres Strait Islander people in the total sample with three or more stresses. In comparing the two groups, the participants in the mental health and emotional well-being difficulty group have a 3.09-fold likelihood of not being able to find a job, a 7.74-fold likelihood of losing a job and a 2.76-fold likelihood of feeling discrimination or racism compared with those in the normal group. Having three or more stress events results in an 8.75-fold likelihood of having mental health and emotional well-being difficulties compared with those who did not experience any stressful events. People who have mental health and emotional well-being difficulties were 11 times more likely to experience clinically diagnosed depression compared with people who were in the normal group.

Table 2. Stressful events

\begin{tabular}{|c|c|c|c|c|c|c|}
\hline \multirow[t]{2}{*}{ Variables } & \multicolumn{2}{|c|}{$\begin{array}{l}\text { Normal } \\
(\mathrm{N}=78)\end{array}$} & \multicolumn{2}{|c|}{$\begin{array}{l}\text { MH and Emotional Well- } \\
\text { being Difficulties }(\mathrm{N}=77)\end{array}$} & \multirow[t]{2}{*}{ Odds Ratio } & \multirow[t]{2}{*}{$\mathrm{P}$} \\
\hline & $\begin{array}{c}\text { No } \\
\%\end{array}$ & $\begin{array}{l}\text { Yes } \\
\%\end{array}$ & $\begin{array}{c}\text { No } \\
\%\end{array}$ & $\begin{array}{c}\text { Yes } \\
\%\end{array}$ & & \\
\hline Serious accident & $93.3 \%$ & $6.7 \%$ & $94.7 \%$ & $5.3 \%$ & $0.47(0.04-5.33)$ & 0.54 \\
\hline $\begin{array}{l}\text { Death of family member or } \\
\text { friend }\end{array}$ & $36.4 \%$ & $63.6 \%$ & $26.0 \%$ & $74.0 \%$ & $1.08(0.47-2.52)$ & 0.85 \\
\hline Divorce or separation & $90.9 \%$ & $9.1 \%$ & $87.0 \%$ & $13.0 \%$ & $1.50(0.39-5.73)$ & 0.55 \\
\hline Not able to get a job & $89.6 \%$ & $10.4 \%$ & $64.9 \%$ & $35.1 \%$ & $3.09(0.99-9.59)$ & $0.05^{*}$ \\
\hline Lost job & $96.1 \%$ & $3.9 \%$ & $88.3 \%$ & $11.7 \%$ & $7.74(0.91-65.81)$ & $0.05^{*}$ \\
\hline Alcohol related problems & $92.2 \%$ & $7.8 \%$ & $90.8 \%$ & $9.2 \%$ & $0.95(0.12-7.09)$ & 0.96 \\
\hline Drug related problems & $96.1 \%$ & $3.9 \%$ & $90.9 \%$ & $79.1 \%$ & $0.30(0.03-3.03)$ & 0.31 \\
\hline $\begin{array}{l}\text { Seeing fights or people beaten } \\
\text { up }\end{array}$ & $83.1 \%$ & $16.9 \%$ & $63.6 \%$ & $36.4 \%$ & $2.76(0.88-8.87)$ & $0.006^{* *}$ \\
\hline Abuse or violent crime & $88.2 \%$ & $11.8 \%$ & $79.2 \%$ & $20.8 \%$ & $1.40(0.41-4.80)$ & 0.59 \\
\hline Trouble with the police & $90.9 \%$ & $9.1 \%$ & $81.6 \%$ & $18.4 \%$ & $3.78(0.74-19.32)$ & 0.11 \\
\hline Gambling problem & $92.3 \%$ & $7.7 \%$ & $87.0 \%$ & $13.0 \%$ & $4.10(0.44-38.23)$ & 0.22 \\
\hline Member of family sent to jail & $79.5 \%$ & $20.5 \%$ & $72.7 \%$ & $27.3 \%$ & $1.64(0.49-5.49)$ & 0.42 \\
\hline $\begin{array}{l}\text { Overcrowding at home (more } \\
\text { than } 10 \text { people) }\end{array}$ & $93.5 \%$ & $6.5 \%$ & $83.1 \%$ & $16.9 \%$ & $1.30(0.27-6.18)$ & $0.05^{*}$ \\
\hline Discrimination/ Racism & $83.1 \%$ & $16.9 \%$ & $59.2 \%$ & $40.8 \%$ & $3.43(1.25-9.37)$ & $0.001 * * *$ \\
\hline $\begin{array}{l}\text { 15. Vandalism or Malicious } \\
\text { damage to property }\end{array}$ & $96.1 \%$ & $3.9 \%$ & $82.9 \%$ & $17.1 \%$ & $2.46(0.59-10.20)$ & $0.008 * *$ \\
\hline \multicolumn{7}{|l|}{ 16.Stress } \\
\hline No stress & \multicolumn{2}{|c|}{$23.8 \%$} & \multicolumn{2}{|c|}{$8.9 \%$} & 1 (Ref) & \\
\hline 1 stress & \multicolumn{2}{|c|}{$40.5 \%$} & \multicolumn{2}{|c|}{$17.8 \%$} & $1.17(0.28-4.93)$ & 0.82 \\
\hline 2 stress & \multicolumn{2}{|c|}{$23.8 \%$} & \multicolumn{2}{|c|}{$26.6 \%$} & $3.00(0.72-12.55)$ & 0.13 \\
\hline 3 or more stress & \multicolumn{2}{|c|}{$11.9 \%$} & \multicolumn{2}{|c|}{$46.7 \%$} & $8.75(2.01-38.14)$ & $0.002 * *$ \\
\hline \multicolumn{7}{|l|}{ 17. Depression } \\
\hline No depression & \multicolumn{2}{|c|}{$94.9 \%$} & \multicolumn{2}{|c|}{$62.1 \%$} & 1 (Ref) & $0.001 * * *$ \\
\hline Depression & \multicolumn{2}{|l|}{$5.1 \%$} & \multicolumn{2}{|l|}{$37.9 \%$} & $11.39(4.21-30.56)$ & \\
\hline
\end{tabular}


Table 3. Difference between Depression and Non-depression Group in Resilience

\begin{tabular}{|c|c|c|c|c|}
\hline & $\begin{array}{c}\text { Normal Mental } \\
\text { Health } \\
\text { Mean } \\
(\mathrm{SD})(\mathrm{n}=78)\end{array}$ & $\begin{array}{c}\text { MH Difficulties } \\
\text { Mean (SD) } \\
(\mathrm{n}=77)\end{array}$ & $\mathrm{F}$ & $\mathrm{P}$ \\
\hline $\begin{array}{l}\text { 1. I tend to bounce back quickly after the stressful event I tend } \\
\text { to bounce back (R) }\end{array}$ & $1.42(0.64)$ & $1.06(0.52)$ & 3.78 & $0.001 * * *$ \\
\hline 2. It takes me a long time to get through stressful events (R) & $1.10(0.75)$ & $1.03(0.56)$ & 0.73 & 0.47 \\
\hline 3. It's easy for me to get over when something bad happens (R) & $1.14(0.68)$ & $0.99(0.58)$ & 1.53 & 0.13 \\
\hline 4. I usually come through difficult times with little trouble (R) & $1.08(0.66)$ & $0.92(0.53)$ & 1.60 & 0.11 \\
\hline $\begin{array}{l}\text { 5. I tend to take a long time to get over difficult things in my } \\
\text { life-Reversed (R) }\end{array}$ & $1.17(0.75)$ & $0.97(0.57)$ & 1.81 & 0.07 \\
\hline 6. I have someone to talk to about decisions in my life. & $1.45(0.74)$ & $1.29(0.73)$ & 1.43 & 0.15 \\
\hline 7. When I feel lonely, there are several people I can talk to. & $1.48(0.66)$ & $1.29(0.73)$ & 1.66 & $0.10^{*}$ \\
\hline 8. I have close relationships that make me feel good. & $1.67(0.57)$ & $1.39(0.69)$ & 2.71 & $0.007 * *$ \\
\hline 9. There are people I know that will help me if I really need it. & $1.68(0.59)$ & $1.59(0.52)$ & 0.89 & 0.38 \\
\hline 10. I have close relationships that help me cope with stress. & $1.62(0.65)$ & $1.45(0.65)$ & 1.56 & 0.12 \\
\hline 11. There are people who appreciate me for who I am. & $1.68(0.55)$ & $1.50(0.60)$ & 1.94 & $0.05 *$ \\
\hline $\begin{array}{l}\text { 12. I feel a strong emotional tie with at least one other person in } \\
\text { this community. }\end{array}$ & $1.58(0.69)$ & $1.53(0.58)$ & 0.49 & 0.62 \\
\hline 13. I feel valued in this community. & $1.55(0.64)$ & $1.34(0.66)$ & 1.99 & $0.05 *$ \\
\hline 14. I trust people in this community & $1.50(0.64)$ & $1.14(0.66)$ & 3.41 & $0.001 * * *$ \\
\hline 15. I feel safe walking in the dark in this community. & $1.06(0.74)$ & $0.97(0.79)$ & 0.73 & 0.47 \\
\hline Total ability to bounce back & $6.85(2.11)$ & $5.17(1.68)$ & 3.31 & $0.002 * *$ \\
\hline Total emotional and esteem support & $12.52(2.38)$ & $10.89(3.07)$ & 2.14 & $0.04 *$ \\
\hline Total community support & $4.20(1.44)$ & $3.33(1.69)$ & 2.02 & $0.05^{*}$ \\
\hline
\end{tabular}

MANOVA tests were used to compare the difference between mental health and emotional wellbeing difficulties group and normal group. Significant level is set up at $\mathrm{P}<0.05$ level

Table 3 shows the results of MANOVA analyses examining the difference in resilience between the two groups. Those in the mental health and emotional well-being difficulty group had a statistically lower resilience score than the normal mental health group in their responses in the following categories:

(a) the ability to bounce back quickly after a stressful event

(b) the capacity to get through stressful and difficult life events

(c) having access to people's help when it is needed

(d) having a close relationship that helps to cope with stress

(e) having people who appreciate you for who you are

(f) feeling valued in the community

(g) trusting people in the community

This suggests that people in this group had a much lower ability to cope with stress and had poor social support and sense of community connectedness.

In the structural equation models, it was found that there is a significant direct relationship between stress and mental health and emotional well-being difficulties (Fig.1). When resilience is added to the model, it significantly mediates the relationship between stress and mental health and emotional well-being difficulties, as the total effect of stress on mental health and emotional well-being significantly increased from 0.28 to 2.09 . The findings indicate that resilience can modify the effect of stress on mental health and emotional well-being in Aboriginal and Torres Strait Islander people.

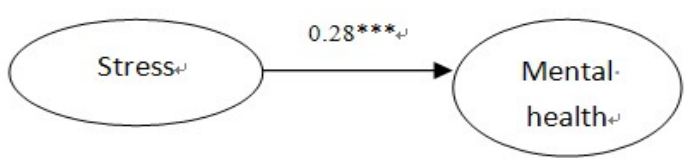

Fit indices results: $\chi 2=0, \mathrm{P}>0.05, \mathrm{CFI}=1.00, \mathrm{TLI}=1.00$, SRMR $=0$

Figure 1. Relationship between stress and mental health and emotional wellbeing

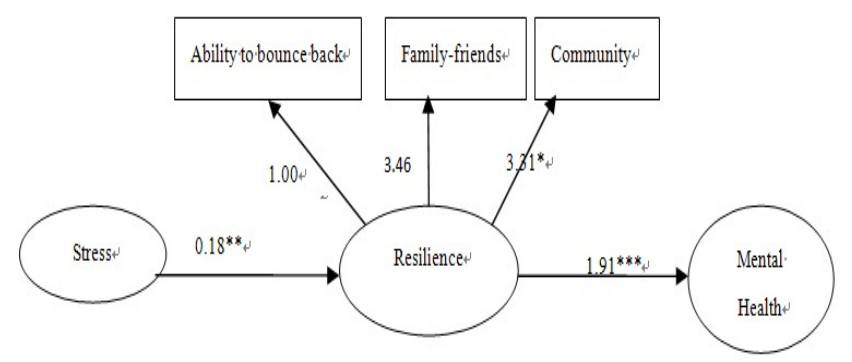

Fit Indices results: $\chi^{2}=3.1, \mathrm{CFI}=0.90, \mathrm{TLI}=0.85, \mathrm{SRMR}=0.07$

Figure 2. Relationship between stress and general mental health and emotional wellbeing mediated by resilience

\section{Discussion}

To our knowledge, this is the first study to examine resilience and stress associated with mental health and emotional well-being difficulties in a high-risk sample of Aboriginal and Torres Strait Islander adults who attended Aboriginal CCHSs. The measure of IRIS is significantly related to clinically diagnosed depression in this study, indicating its sensitivity in differentiating people who were experiencing 
mental health and emotional well-being difficulties and people with normal mental health status. Significantly, $49.7 \%$ of participants had self-reported mental health and emotional well-being difficulties in this study. This high percentage is significantly related to having three or more stresses. The prevalence of self-reported high levels of stress $(29.3 \%)$ is similar to the estimates from the National Health Survey Results in which $26.6 \%$ of people are reported to have high to very high stress levels ${ }^{(4)}$.

Consistent with prior studies of other populations ${ }^{(17,18)}$, we found a significantly smaller number of stressors in the normal mental health group than in the mental health and emotional well-being difficulty group. The fact that job loss, the inability to find jobs and the subjective experience of discrimination and racism occur more frequently in the latter group than in the former in our sample further confirms that disadvantage in the Aboriginal and Torres Strait Islander population is a significant risk factor for experiencing mental health and emotional well-being difficulties ${ }^{(19)}$. There was also a significant difference between the two groups in relation to having three or more stressful events, suggesting that the stress load is an important predictor of mental health and emotional well-being difficulties. Of the factors that were examined that include adverse life events, resilience was found to be related to mental health and emotional well-being difficulties.

\subsection{Stress}

Indigenous disadvantage is well documented and acknowledged to be directly related to morbidity and mortality $^{(2)}$. The results of the current study are consistent with those of previous studies, which found that a combination of factors is responsible for their poor mental health, including lack of employment, family violence, past government practices (for example, the Stolen Generations), substance abuse and poverty ${ }^{(20,21)}$. The demonstration of stress related to violence and their association with mental health and emotional well-being difficulties is quite graphic in this group of people. For example, up to $20 \%$ of the mental health and emotional wellbeing difficulty group had witnessed fights or assaults, $10 \%$ of the group as a whole reported trouble with police and $40.8 \%$ felt they experienced discrimination.

The findings of the present study further indicate that resilience significantly mediates the association of stress with mental health and emotional well-being and suggests that resilience is an important trait of individuals who have the ability to return to a previous level of functioning (i.e. bouncing back or recovery) or individuals who do not have mental health and emotional well-being difficulties following stressful events because of social and community support ${ }^{(22)}$.

\subsection{Resilience}

Results from this study confirm previous research that found associations between resilience in the face of stress and positive mental health outcomes ${ }^{(23)}$. In line with arguments proposed by Agnes ${ }^{(24)}$, a strong ability to bounce back from previous trauma exposure may promote resilient outcomes, and may be central to the process of recovery from stress events and not developing mental health or emotional well-being difficulties.

In this sample, a lack of social support was associated with mental health and emotional well-being difficulties. This is consistent with an Australian Government review that identified mental health and social and emotional well-being as crucial for achieving better health in Aboriginal and Torres Strait Islander people ${ }^{(25)}$. The review found that Aboriginal and Torres Strait Islander people had poor mental health literacy rates, coupled with a reluctance to draw on existing and new forms of support (for example, counselling services offered by the Aboriginal CCHS). The relationship between social support and mental health has been widely studied ${ }^{(26)}$. An individual's ability to draw on relationships with others as a resource in times of stress is a key component of social support, which has been found to buffer against the development of post-traumatic stress disorder ${ }^{(27)}$.

It was found that social connectedness is linked to mental health ${ }^{(28)}$. However, the conceptualisation of social connectedness itself has been contested and its utility in contexts such as Indigenous Australia challenged ${ }^{(29)}$. Our findings indicate that a low level of social connectedness is significantly related to mental health and emotional well-being difficulties in Aboriginal and Torres Strait Islander people. People who feel less valued and have low levels of trust in people in the community were at increased risk of experiencing mental health and emotional well-being difficulties. As Whiteford et al state, 'social connectedness can enhance mental health and reduce the impact of mental illness, ${ }^{\text {(28) }}$. Our findings also support those of Brough et $\mathrm{al}^{(30)}$ that Aboriginal and Torres Strait Islander people seek both acknowledgement of their Aboriginality as well as the freedom to participate in the multicultural space of a large Australian city. Being 'connected' is clearly dependent on their identity, which determines the opportunities available to them.

One limitation of this study is that mental health and emotional well-being difficulties were assessed by a self-reported questionnaire as a screening tool, which might have overestimated the levels of mental health and emotional well-being difficulties. Further research using structured diagnostic interviews is required to ensure the sample population meets the diagnostic requirement for mental health problems. Moreover, the study design is cross-sectional in nature, which may limit the conclusions that may be drawn.

In conclusion, Aboriginal and Torres Strait Islander people who have high levels of stress are at increased risk of experiencing mental health and emotional well-being difficulties. An important step in reducing this risk is to acknowledge their individual abilities to cope with stress and to provide social support through primary health services, and educational and employment opportunities. Improving our 
understanding of psychological characteristics associated with resilience in the face of stress can inform prevention and treatment interventions for stress-exposed individuals. This could occur in a number of ways, including through service delivery mechanisms and government policy to reduce the incidence of stressful life events. A focus of mental health promotion initiatives at the community level should be on participatory community projects that can build skills, confidence and ability. A major determinant of social support is the existence of support structures within Aboriginal and Torres Strait communities that people feel comfortable and safe accessing.

\section{ACKNOWLEDGEMENTS}

The authors received financial support from Griffith Health Institute of Griffith University and Queensland Aboriginal and Islander Health Council in Australia. The authors also wish to acknowledge the support of the following Aboriginal Community Controlled Health Services: Brisbane Kambu Medical Services Inc., Kalwun Health Service, Aboriginal and Torres Strait Islander Community Health Service Brisbane Ltd, Goolburri Health Advancement Corporation, and Warwick Community Peace Festival. The authors also wish to thank all participants' participation from five Aboriginal and Torres Strait Islander communities.

\section{REFERENCES}

[1] Thomson N. The health of Indigenous Australians. London: Oxford University Press; 2004.

[2] Trewin D, Madden R. The Health and Welfare of Australia's Aboriginal and Torres Strait Islander Peoples. Canberra: Australian Bureau of Statistics; Australian Institute of Health and Welfare2003.

[3] Australian Bureau of Statistics. The Health and Welfare of Australia's Aboriginal and Torres Strait Islander Peoples. Canberra: ABS2008 Contract No.: 4704.0. 2008.

[4] Alim TN, Feder A, Graves RE, Wang Y, Weaver J, Westphal $\mathrm{M}$, et al. Trauma, resilience, and recovery in a high-risk African-American population. Am J Psychiatry.2008;165:15 $66-75$.

[5] Werner EE, Smith RS. Journeys from Childhood to Midlife: Risk, Resilience, and Recovery Introduction to the Special Issue on Resilience. J Subst Use. 2001;39(5):657-70.

[6] Bonanno GA. Loss, trauma, and human resilience: have we underestimated the human capacity to thrive after extremely aversive events? Am Psychol. 2004;59:20-8.

[7] Masten AS, Coatsworth JD. The development of competence in favorable and unfavorable environments: lessons from research on successful children. Am Psychol. 1998;53:205-20.
[8] Sun J, Stewart D. Development of population based resilience measures in the primary school setting. Health Educ. 2007;107(6):575-99.

[9] Australian Bureau of Statistics. National Aboriginal and Torres Strait Islander Social Survey. Canberra: Australian Government Publishing Service2002.

[10] Kowal E, Gunthorpe W, Bailie RS. Measuring emotional and social wellbeing in Aboriginal and Torres Strait Islander populations: An analysis of a Negative Life Events Scale. Int J Equity Health. 2007;6(18):1-12.

[11] Schlesinger CM, Ober C, McCarthy MM, Watson JD, Seinen A. The development and validation of the Indigenous Risk Impact Screen (IRIS): A 13-item screening instrument for alcohol and drug and mental health risk. Drug Alcohol Rev. 2007;26:109 - 17 .

[12] mith BW, Dalen J, Wiggins K, Tooley E, Christopher P, Bernard J. The Brief Resilience Scale: Assessing the ability to bounce back. Int J Behav Med. 2008;15:194-200.

[13] McCubbin HI, Paterson J, Glynn T. Social support index. In: McCubbin HI, Thompson AI, McCubbin MA, editors. Family assessment: Resiliency, coping and adaptation: Inventories of research and practice. Madison, Wisconsin: University of Wisconsin Publishers; 1987. p. 389.

[14] First MB, Gibbon M, Spitzer RL, Williams JBW. Structured Clinical Interview for DSM-IV Axis I Disorders: Nonpatient Edition (SCID-I/NP). New York: Biometrics Research Department, New York State Psychiatric Institute; 1996.

[15] Muthen LK, Muthen BO. Mplus User's Guide. Los Angeles, CA: Muthen \& Muthen; 1998-2010.

[16] Hu LT, Bentler PM. Evaluating model fit. . In: Hoyle RH, editor. Structural equation modeling: Concepts, issues, and applications Thousand Oaks, CA: Sage; 1995. p. 76-99.

[17] Breslau N, Kessler RC, Chilcoat HD, Schultz LR, Davis GC, Andreski P. Trauma and posttraumatic stress disorder in the community: The 1996: Detroit area survey of trauma. Arch Gen Psychiatry. 1998;55:626-32.

[18] Witvliet CVO, Phipps KA, Feldman ME, Beckham JC. Posttraumatic mental and physical health correlates of forgiveness and religious coping in military veterans. J Trauma Stress. 2004;17:269-73.

[19] Butler T, Allnutt S, Kariminia A, Cain D. Mental health status of Aboriginal and non-Aboriginal prisoners. Aust $\mathrm{N} \mathrm{Z} \mathrm{J}$ Psychiatry. 2007;41:429-35.

[20] Emden C, Kowanko I, De Crespigny C, Murray G. Better medication management for Indigenous Australians: Findings from the field. Aust J Prim Health. 2005;11:80-90.

[21] O'Brien A. Factors shaping Indigenous mental health: An ethnographic account of growing up Koori from a Gubba perspective. Aust J Holist Nurs. 2005;12:11-20.

[22] Carver CS. Resilience and thriving: Issues, models, and linkages. J Soc Issues. 1998;54:245-66.

[23] Brewin CR, Andrews B, Valentine JD. Meta-analysis of risk factors for posttraumatic stress disorder in trauma-exposed adults. J Consult Clin Psychol. 2000;68:748-66. 
[24] Agnes M. Webster's new college dictionary. Agnes, M. ed. Cleveland, OH: Wiley; 2005.

[25] National Aboriginal and Torres Strait Islander Health Council. National Strategic Framework for Aboriginal and Torres Strait Islander Health Framework for action by Governments Canberra: NATSIHC2003.

[26] Coory MD, Green AC, Stirling J, Valery PC. Survival of Indigenous and non-Indigenous Queenslanders after a diagnosis of lung cancer: A matched cohort study. Med J Aust. 2008;188:562-6.

[27] Charuvastra A, Cloitre M. Social bonds and posttraumatic stress disorder. Annu Rev Psychol. 2007.
[28] Whiteford H, Cullen M, Baingana F. Social capital and mental health. Geneva: World Health Organization2005.

[29] Hunter B. Taming the Social Capital Hydra? Indigenous Poverty, Social Capital Theory and Measurement. Canberra: Centre for Aboriginal Economic Policy Research, The Australian National University, 2004 Contract No.: Discussion Paper No. 261.

[30] Brough M, Bond C, Hunt J, Jenkins D, Shannon C, Schubert L. Social capital meets identity: Aboriginality in an urban setting. J Sociol. 2006;42(4):396-411. 